\title{
Evaluation of lipid profile and apolipoproteins in cord blood from Tribal and nontribal population of Udaipur region, India
}

\author{
Suman Jain*, Sonal Sogani \\ Department of Biochemistry, Pacific Institute of Medical sciences, Udaipur, Rajasthan, India \\ Received: 03 October 2015 \\ Revised: 19 October 2015 \\ Accepted: 04 November 2015 \\ *Correspondence: \\ Dr. Suman Jain, \\ E-mail: sumannemijain@yahoo.com
}

Copyright: (C) the author(s), publisher and licensee Medip Academy. This is an open-access article distributed under the terms of the Creative Commons Attribution Non-Commercial License, which permits unrestricted non-commercial use, distribution, and reproduction in any medium, provided the original work is properly cited.

\begin{abstract}
Background: Cardiovascular diseases are the leading cause of mortality in India. The important factor associated is dyslipidemia. A strong relationship has been seen in epidemiological studies between cholesterol and cardiovascular disease. The present study was planned to analyze cord blood lipid profile, apolipoproteins and atherogenic index in tribal and nontribal population and compare them gender wise.

Methods: Our study group consisted of 250 healthy full-term newborn. The cord blood was collected immediately after a normal delivery. The blood was tested to determine lipid profile, apolipoproteins and atherogenic index.

Results: The results showed that the levels of lipid profile, apolipoproteins and ratio (TC/HDL, TC/LDL, HDL/LDL, and LDL/HDL) were higher in non-tribal population than tribal ones. Gender wise comparison revealed higher levels in male non-tribal neonates as compared to female non-tribal neonates. The apolipoproteinB and Atherogenic index (ApoB/ApoA-1) were higher in females than male non-tribal neonates in cord blood. The trends were reversed in the tribal population.

Conclusions: The result concluded that tribal and non-tribal population, also female and male neonates have genetic variation and difference in lipid metabolism.
\end{abstract}

Keywords: Lipid profile, Apolipoproteins, Atherogenic index, Cord blood, Tribal

\section{INTRODUCTION}

Atherosclerosis is the major cause of global mortality and will continue to dominate trend in future. ${ }^{1}$ Atherosclerosis is a process that begins in early in life and progresses silently for decades, some of scientist believe that atherosclerotic lesions may have its genesis during childhood., ${ }^{2,3}$ Due to urbanization and mechanization within the last decades have an effect on the occurrence of civilization illnesses and people's lifestyle has changed. ${ }^{4}$

A foetus needs a considerable amount of cholesterol for development of tissues and organs. After birth lipid transport system is transformed from one containing low VLDL and LDL levels to adult system with a relatively high LDL levels which continues to increase with age. Cord blood contains all adult lipoproteins and apolipoproteins. ${ }^{5}$ Abnormal lipid profiles in childhood persist into adult life and elevated $\mathrm{ApoB}$ in adult have been linked to atherosclerosis in later life. ${ }^{6}$ On the basis of research conducted have shown that the high prevalence of atherosclerosis risk factor and increased morbidity and mortality due to cardiological diseases within the urban areas is more than rural areas. ${ }^{7,8}$

Disorders of lipid metabolism and elevated levels of low density lipoprotein (LDL-C), total cholesterol (TC) and apolipoproteinB (ApoB) levels in young adults have been connected with cardiovascular diseases in the life. ${ }^{6}$ Dirisamer et al have showed evidence that levels of ApoB, ApoB/apoA-1 ratio as well as LDL-C concentrations are sensitive indicators for later coronary heart disease in children. ${ }^{9}$ ApoB/ ApoA-1 ratio known as atherogenic index is sensitive marker to track coronary artery disease is found to be measured closely during first 
year of life. ${ }^{10}$ Screening patients for ApoA-1 and ApoB levels may significantly improve ability to properly evaluate CAD risk. ${ }^{11}$ Therefore aim of the present study is check the influence of tribal and non-tribal environment on the parameters of lipid profile and apolipoproteins in the cord blood and compare them in males and female neonates.

\section{METHODS}

The present prospective study was conducted in the department of Biochemistry, Geetanjali Medical College and hospital, Udaipur.

A total of 250 healthy neonates (following healthy normotensive pregnancy) were included in the study which were divided on the basis of environmental genetic variant as Tribal $(\mathrm{N}=31)$ and non-tribal $(\mathrm{N}=219)$ and further subdivided according to gender (male and females).

\section{Inclusion criteria for mothers}

Healthy mother only on iron folic acid and calcium supplementation were included.

\section{Exclusion criteria for mothers}

History with alcoholism, smoking hypertension, thyroid disorders, diabetes mellitus, renal diseases, hypercholesterolemia, twins, liver diseases, tuberculosis and asthma, pregnancy induced hypertension were excluded.

\section{Inclusion criteria for neonates}

Gestational age between 35-42 weeks and Absence of congenital anomalies were included.

\section{Exclusion criteria for neonates}

Congenital malformations, Neonates born to mother with maternal illness, Neonates with perinatal problems like hypoglycaemia, pathological jaundice, Intrumental delivery including extraction and also Neonates with hypoxic ischemic encephalopathy and sepsis were excluded.

\section{Sample collection}

After delivery and cord clamping umbilical venous blood was taken from maternal umbilical end. Serum was separated and analysed for lipid profile (total cholesterol, triglyceride, HDL-C, LDL-C, and VLDL-C) and Apolipoproteins (ApoB, ApoA-1).

\section{Estimations}

The levels of triglyceride, total cholesterol and HDL-C were assayed with reagent by Roche. The concentrations of LDL-C and VLDL-C was defined by using the formula given by Friedewald. ${ }^{12}$ Apolipoproteins were assayed by immunoturbidimetric method. ${ }^{13}$ The assay were performed with cobas c311 fully auto analyser instrument.

\section{Statistical analysis}

The mean and standard deviation has been used to define data in each group. These data were compared and significance was calculated between Rural and urban neonates and also between male and female neonates using unpaired ' $\mathrm{t}$ ' test. The p-value less than 0.05 were considered as significant and values less than 0.001 were considered as highly significant. Graph Pad prism version 6 software was used for analysis.

\section{RESULTS}

Table 1 shows comparison between non-tribal and tribal population. The results showed that the levels of lipid profile including total cholesterol, triglyceride, high density lipoprotein, low density lipoprotein, and very low density lipoprotein, apolipoproteins (ApoB and ApoA) and ratio (TC/HDL, TC/LDL, HDL/LDL, LDL/HDL) were higher in non-tribal population than Tribal ones. The atherogenic index was lower in tribal population than in non-tribal populations, showing that environment effect on atherogenic index. The significance of variance showed no significance when compared non-tribal and tribal populations.

The table2 showed that total cholesterol (TC), triglyceride (TG), lipoproteins (HDL-C, LDL-C, VLDL$\mathrm{C}$ ), and ratios (TC/HDL, TC/LDL, HDL/LDL, LDL/HDL) were higher in male nontribal neonates as compared to female non-tribal neonates. The apolipoproteinB and Atherogenic index (ApoB/ApoA-1) were lower in females than male non-tribal neonates in cord blood. Apolipoprotein A-1 was higher in female as compared to male non-tribal neonates.

No statistical significant differences between mean levels of lipid profile, apolipoprotein and atherogenic index in male and female non-tribal population was seen. P-values less than 0.001 were highly significant and less than 0.05 were significant but were non-significant if the values were more than 0.05 .

The trends were reversed in the tribal population. The mean levels of all parameters (lipid profile, apolipoproteins and atherogenic index) except ApoA-1 were higher in females as compared to male tribal neonates. The apolipoprotein A was higher in male tribal population than female tribal ones.

The significant variance between male and female tribal neonates were non- significant $(\mathrm{p}>0.05)$ (Table 3$)$. 


\section{DISCUSSION}

According to genetic variation we divided the population as tribal and nontribal because they have distinct differences in their living style and socioeconomic profile. S. Basu (2000) presented the socio-economic status of several scheduled tribes inhabiting in various regions of our sub-continent. They showed that the lifestyle, customs and traditions are quite different from the rural and urban populations also they lived in their own world. They are socially backward and have no health facilities and jobs for their daily needs. ${ }^{14}$

Table 1: Serum lipid profile, apolipoproteins and atherogenic index in cord blood from non-tribal and tribal population.

\begin{tabular}{|lllllll|}
\hline No. & Parameters & Non-tribal $(\mathbf{n}=219)$ & & Tribal $(\mathbf{n}=31)$ & P-value \\
& & Mean \pm SD & Range & Mean \pm SD & Range & \\
\hline 1 & Total cholesterol mg/dL & $71.53 \pm 20.12$ & $48-115$ & $71.00 \pm 21.12$ & $35-86$ & 0.89 \\
\hline 2 & Triglyceride $\mathrm{mg} / \mathrm{dL}$ & $55.10 \pm 24.99$ & $36-120$ & $52.70 \pm 26.20$ & $17-38$ & 0.61 \\
\hline 3 & HDL-C $\mathrm{mg} / \mathrm{dL}$ & $33.09 \pm 12.19$ & $19-98$ & $32.29 \pm 16.79$ & $15-108$ & 0.74 \\
\hline 4 & LDL-C $\mathrm{mg} / \mathrm{dL}$ & $31.41 \pm 16.57$ & $21-74$ & $30.78 \pm 20.31$ & $2-69$ & 0.84 \\
\hline 5 & VLDL-C $\mathrm{mg} / \mathrm{dL}$ & $14.29 \pm 11.24$ & $7-77$ & $14.28 \pm 12.94$ & $3-52$ & 0.99 \\
\hline 6 & TC/HDL-C & $4.60 \pm 3.00$ & $2-19$ & $4.04 \pm 3.70$ & $2-21$ & 0.34 \\
\hline 7 & TC/LDL-C & $2.62 \pm 0.75$ & $1-5$ & $2.61 \pm 0.96$ & $1.6-4.6$ & 0.94 \\
\hline 8 & HDL-C/LDL-C & $1.29 \pm 0.67$ & $0.59-4.5$ & $1.28 \pm 0.85$ & $0.5-4.6$ & 0.94 \\
\hline 9 & LDL-C/HDL-C & $1.14 \pm 0.75$ & $0.5-3.4$ & $1.14 \pm 0.87$ & $0.04-29$ & 1.00 \\
\hline 10 & ApolipoproteinB mg/dL & $31.03 \pm 6.5$ & $19-49$ & $30.04 \pm 8.12$ & $17-49$ & 0.44 \\
\hline 11 & Apolipoprotein A-1 mg/dL & $52.22 \pm 9.16$ & $64-70$ & $55.20 \pm 10.79$ & $32-78$ & 0.09 \\
\hline 12 & ApoB/ApoA-1 & $0.61 \pm 0.19$ & $0.27-1.5$ & $0.57 \pm 0.25$ & $0.27-1.4$ & 0.29 \\
\hline
\end{tabular}

Table 2: Serum lipid profile, apolipoproteins and atherogenic index in cord blood of male and female neonates from non-tribal environment.

\begin{tabular}{|lllll|}
\hline No. & Parameters & Non-tribal $(\mathrm{N}=219)$ & Mean \pm SD & P-Value \\
\hline & & Male $(\mathrm{N}=127)$ & Female $(\mathrm{N}=92)$ & 0.87 \\
\hline 1 & Total cholesterol mg/dL & $71.73 \pm 19.93$ & $71.31 \pm 20.42$ & 0.31 \\
\hline 2 & Triglyceride mg/dL & $56.49 \pm 25.59$ & $53.05 \pm 24.14$ & 0.91 \\
\hline 3 & HDL-C mg/dL & $31.19 \pm 12.37$ & $31.02 \pm 12.03$ & 0.94 \\
\hline 4 & LDL-C mg/dL & $32.13 \pm 15.76$ & $31.96 \pm 17.61$ & 0.52 \\
\hline 5 & VLDL-C mg/dL & $14.49 \pm 11.91$ & $13.50 \pm 10.28$ & 0.77 \\
\hline 6 & TC/HDL-C & $3.55 \pm 3.00$ & $3.67 \pm 3.02$ & 0.62 \\
\hline 7 & TC/LDL-C & $2.20 \pm 0.78$ & $2.15 \pm 0.71$ & 0.62 \\
\hline 8 & HDL-C/LDL-C & $1.24 \pm 0.66$ & $1.21 \pm 0.68$ & 0.74 \\
\hline 9 & LDL-C/HDL-C & $1.19 \pm 0.71$ & $1.17 \pm 0.79$ & 0.84 \\
\hline 10 & ApolipoproteinB mg/dL & $31.55 \pm 6.33$ & $30.32 \pm 6.86$ & 0.17 \\
\hline 11 & Apolipoprotein A-1 mg/dL & $51.03 \pm 9.22$ & $53.52 \pm 9.12$ & $0.04 *$ \\
\hline 12 & ApoB/ApoA-1 & $0.64 \pm 0.18$ & $0.59 \pm 0.20$ & 0.05 \\
\hline
\end{tabular}

Maternal mortality was reported to be high among various tribal groups. The chief causes of maternal mortality were found to be unhygienic and primitive practices for parturition. The health, nutrition and medico-genetic problems of diverse tribal groups have been found to be unique and present a formidable challenge for which appropriate solutions have to be found out by planning and evolving relevant research studies. $^{15}$
Major lipoprotein in cord blood is high density lipoprotein and in adult is low density lipoprotein. ${ }^{16}$ In general the level of lipid profile, atherogenic index, lipoproteins and their ratio were relatively low in tribal which seemed to be mainly due to their ignorance towards the selection of food. By habit they are non vegetarians and hunting provides them main source of food with fast erosion of forests, strong restriction on hunting of wild animals and prohibitive cost of non 
vegetarians food have resulted in their change of food habits and intake. They still pay very little attention to vegetables and fruits and this is mainly responsible for lower intake of vitamin, mineral and fibrous food. The social factor includes many non-medical factors such as poor quality of life, poor housing and overcrowding, population explosion, under nutrition, lack of education, large families, early marriages, lack of awareness are cause of ignorance to healthy food habits. The studies of Hanumantha Rao showed that intake of protein, calcium, iron, thiamine and niacin were comparable to the recommended allowances in tribal, while the intake of other nutrients such as total fat, energy, vitamin A, riboflavin, vitamin $\mathrm{C}$ and free folic acid were below the recommended levels. ${ }^{17}$ In this study tribal had lower values of total cholesterol, triglyceride, HDL-C, LDL-C and VLDL-C also apolipoprotein A1 which is in agreement with other workers. They showed that tribal are particularly vulnerable to malnutrition because of their geographical isolation, uncertainty of food supply, lack of adequate health care facilities and due to certain traditional belief systems and cultural practices. ${ }^{15}$

Table 3: Serum lipid profile, apolipoproteins and atherogenic index in cord blood of male and female neonates from tribal population.

\begin{tabular}{|lllll|}
\hline No. & Parameters & Tribal $(\mathrm{n}=31)$ & Mean \pm SD & P-value \\
\hline & & Male $(\mathrm{N}=22)$ & Female $(\mathrm{N}=9)$ & \\
\hline 2 & Total cholesterol mg/dL & $64.25 \pm 20.98$ & $77.88 \pm 26.29$ & 0.13 \\
\hline 3 & Triglyceride mg/dL & $50.17 \pm 22.45$ & $64.88 \pm 29.42$ & 0.14 \\
\hline 4 & HDL-C mg/dL & $30.02 \pm 10.49$ & $38.44 \pm 26.91$ & 0.21 \\
\hline 5 & LDL-C mg/dL & $26.97 \pm 17.73$ & $31.04 \pm 22.79$ & 0.59 \\
\hline 6 & VLDL-C mg/dL & $14.78 \pm 11.90$ & $16.40 \pm 14.60$ & 0.74 \\
\hline 7 & TC/HDL-C & $3.63 \pm 1.82$ & $5.10 \pm 1.60$ & $0.04^{*}$ \\
\hline 8 & TC/LDL-C & $2.55 \pm 1.02$ & $2.62 \pm 0.56$ & 0.84 \\
\hline 9 & HDL-C/LDL-C & $1.25 \pm 0.87$ & $1.51 \pm 0.75$ & 0.43 \\
\hline 10 & LDL-C/HDL-C & $1.02 \pm 0.73$ & $0.97 \pm 0.85$ & 0.86 \\
\hline 11 & ApolipoproteinB mg/Dl & $27.99 \pm 7.79$ & $31.52 \pm 11.73$ & 0.33 \\
\hline 12 & Apolipoprotein A-1 mg/dL & $53.30 \pm 13.60$ & $52.86 \pm 12.33$ & 0.93 \\
\hline
\end{tabular}

To check the sex variation in genetic variants if any, subjects were divided into males and females neonates. Our evaluation revealed no significant difference in the levels of lipid profile, apolipoproteins and atherogenic index level; though tend to be higher in non-tribal males. However we find sex wise difference in nontribal male neonates with higher values than female neonates and reverse in tribal female newborns with higher value than male newborns. Total cholesterol, HDL-C, LDL-C in female tribal cord blood are higher as compared to male cord blood levels but the statistical significance was not found. Our findings were similar to the findings of S. kharab and Badiee and also with Bastida. ${ }^{16,18,19}$ This result shows gender related factors could have influenced lipid levels at term period. Obviously there are important mechanism of lipid metabolism and also low nutrient status in mothers of tribal. As per Indian tradition and social dictates, women are usually a last beneficial on the dining table or in the kitchen. The comparison between male and female non-tribal showed higher levels in males than females which were in reverse trend in tribal population where females had higher levels than males the reason could only be genetic variation. The study of Pandey et al concluded that all these population groups arose through a common ancestor and changed gene frequency among them is due to evolutionary forces like selection, migration, temporal variation and genetic drift. However, these populations retain their separate entities by practicing endogamy. Gene diversity analysis reveals that these tribal groups are at an early stage of genetic differentiation. $^{20}$ There is no such literature available about genetic status comparison. The incidence was higher in tribal female neonates but is lower in non-tribal females as compared to male neonates. The reason could be genetic variation. The tribal male neonates are inborn dominance due to their father's personal habits like smoking, alcoholism, and female showed lower level in non-tribal. The obsession of modernization and Industrialization has led to an unusual increase in smoke, dust and pollution. People in general are developing a bad habit of spending more on items other than food with this result, poor and unbalanced nutrition is adding dimensions to health. Contaminated food and drinks are frequently consumed. The result shows that female and male have genetic variation and different lipid metabolism. 


\section{CONCLUSIONS}

Treating the hypertension does not alter the progression of disease but early treatment decreases not only the frequency of hypertensive crisis, but also the rate of neonatal complications. Antihypertensive medications are mainly used to prevent or treat severe hypertension, to prolong pregnancy for as long as safely possible thereby maximizing the gestational age of the infant, and to minimize fetal exposure to medications that may have adverse effects.

This study confirms the previous findings that labetalol is an effective and safe drug for use in the control of blood pressure in pregnancy-induced hypertension. The low incidence of maternal and foetal side-effects together with the excellent perinatal outcome in a condition usually accompanied by a high maternal and foetal mortality and morbidity confirms its suitability for use during pregnancy. Nifedipine is equally efficacious and better tolerated compared to methyldopa in the treatment of new onset hypertension during pregnancy. However, the effect on fetal and maternal outcomes must be considered before selecting any drug in the treatment of hypertensive disorders of pregnancy.

Awareness regarding PIH and availability of easily accessible and affordable health care services to rural population and poor people is important which shall be helpful in reducing the PIH related morbidity and mortality.

\section{CONCLUSION}

The studies to evaluate lipid levels in cord blood of neonates from non-tribal and tribal population have not proved any significant difference between the studied groups. The result shows that tribal and non-tribal population, also female and male neonates have genetic variation and difference in lipid metabolism.

\section{ACKNOWLEDGEMENTS}

We sincerely thank R.N.T. Medical College and associated hospital, Udaipur for extending all the facilities for conducting the work. Authors acknowledge the immense help received from the scholars whose articles are cited and included in references of this manuscript. The authors are also grateful to authors/editors/publishers of all those articles, journals and books from where the literature for this article has been reviewed and discussed.

Funding: No funding sources Conflict of interest: None declared

Ethical approval: The study was approved by the Institutional Ethics Committee

\section{REFERENCES}

1. World health organization, world health statistics, 2009.

2. Mc Gill HJr, Mc Mahan CA. Determinants of atherosclerosis in the young, pathobiological determinats of Atherosclerosis in youth (PDAY) Research Group. AM J Cardiol. 1998;82(10B):30T$6 \mathrm{~T}$.

3. MC Millan GC. Development of atherosclerosis. Am J cardiol. 1973;31:542-6.

4. Elzbieta Pac - Kozuchowska. Evaluation of lipids, lipoproteins and Apolipoproteins concentrations in cord blood serum of new borns from rural and urban environments. Ann Agric Environ Med. 2007;14:259.

5. Mc conathy WJ, Lane DM. Studies on the apolipo proteins and lipoproteins of cord serum pediatr. Res. 1980;14:757-61.

6. Klag MJ, Ford DE, Mead LA. Serum cholesterol in young men and subsequent cardio vascular disease. N Engel J med. 1993;328:313-8.

7. Abdul-Rahim HF, Hussein A, Bjertness E, Giecaman $\mathrm{R}$, Gordon NH, Jervell J. The metabolic syndrome in the west bank population. An urban - rural Comparison. Diabetic care. 2001;24:275-9.

8. Stiernstron EL, Holmberg S, Thelin A, Svardsudd K. A prospective study of morbidity and mortality rates among farmers and rural and urban non-farmers. J. clin Epidemiol. 2001;542:121-6.

9. Dirisamer A, stadler A, Bucek RA, Widhalm K. Apo B - 100 and Apo-B/Apo-A-1 ratio in children and adolescents from families with very early myocardial infarction. Acta paediatr. 2006;95:810-3.

10. Yavuz T, Yavuz O, Ozdemir I, Afsar Y. Cord blood lipoprotein profile after magnesium sulphate treatment in Pre - eclamptic patients. Acta paediatr. 2006;95:1224-7.

11. Sattar N, Williams K, Siriderman AD, Agostino RB, Haffner SM. Comparison of the associations of apolipoprotein B and no high density lipoprotein cholesterol with other cardiovascular risk factors in patients with the metabolic syndrome in the insulin resistance Atherosclerosis study. Circulation. 2004;110:2687-93.

12. Friedelwald WT, Levy RI Fredrickson DS. Estimation of the concentration of low-density lipoprotein cholesterol in plasma, without use of the preparative ultracentrifuge. Clin Chem. 1972;18:499502.

13. Dati F. Estimation of apolipoproteins by immunoturbidimetric method. Lab Med. 1989;13:879.

14. Basu S. Dimensions of tribal health in India: Health and Population - Perspectives and Issues. 2000;23(2):61-70.

15. Rao M, Kumar RH, Venkaiah K, Brahmam GNV. Nutritional Status of Saharia - A Primitive Tribe of Rajasthan J. Hum. Ecol. 2006;19(2):117-23. 
16. Badiee Z, Keilshadi R. Cord blood lipid profile in a population of Iranian term newborns. Pediatr cardiol. 2008;29930:574-9.

17. Rao H, Brahmam D, Rao M, Reddy KG. Nutrition Profile of certain Indian tribes. Proceedings of the National Seminar on Tribal Development: Options, held during May 22-24. Prasanna K. Samal (Ed.). Gyanodaya Prakasham, Nainital, 1996.

18. Kharb S, Kaur A, Nanda S. Comparison of cord blood atherogenic index in males and females. Iranian Cardiovascular Research j. 2010;4(1):35-8.
19. Bastida S, Sanchez- Muniz FJ, Cuesta C, Perea S, Aragones A. male and female cord blood lipoprotein profile differences throughout the term- period. J Perinat med. 1997;25(2):184-91.

20. Pandey BN, Kumari R, Mishra A. Genetic variation and micro-genetic differentiation among tribal populations of Jharkhand, India Scholarly Journal of Agricultural Science. 2012;2(8):147-56.

Cite this article as: Jain S, Sogani S. Evaluation of lipid profile and apolipoproteins in cord blood from Tribal and nontribal population of Udaipur region, India. Int J Reprod Contracept Obstet Gynecol 2015;4:1825-30. 